\title{
O tempo do espectador: a fruição da imagem em movimento no espaço do museu
}

\author{
Cristiane Herres Terraza' \\ Lorena Travassos" \\ I - Instituto Federal de Brasília \\ Brasília (DF), Brasil \\ II - Universidade Nova de Lisboa \\ Lisboa, Portugal
}

Resumo: O artigo dispõe-se a refletir sobre a relação do espectador junto às obras que utilizam a imagem em movimento no espaço do museu e como tal relação gera novos modos de fruição, ressaltando a disponibilidade de tempo dedicado à apreciação das obras. Trata-se de analisar a relação entre o tempo da obra e o tempo do espectador diante de filmes de longa temporalidade, como é o caso das instalações The Clock (2010), de Marclay, e Theresienstadt (2007), de Blaufuks, a partir de conceitos como cinema expandido (PARENTE, 2006) e espectador pensativo (BELLOUR, 1987). Ademais, tem-se em conta o aporte teórico que trata do cinema lento e da emancipação do espectador que se apresenta como responsável por tornar a arte produtiva.

Palavras-Chave: cinema expandido; espectador; espaço museal; estética da recepção.

Abstract: The spectator's time: the aesthetic appreciation of moving images inside the museum The paper proposes to reflect about the spectator's relationship with the works that use the moving image in the museum space and how this relationship generates new ways of fruition, highlighting the time available for the appreciation of the works. It intends to analyze the relationship between the time of the work and the spectator's time on long temporality films, as in the case of installations such as Marclay's The Clock (2007) and Blaufuk's Theresienstadt (2007), using concepts like expanded cinema (PARENTE, 2006) and pensive spectator (BELLOUR, 1987). Furthermore, it regards the theoretical framework that deals with slow film and the emancipation of the spectator that presents itself as responsible for making the art productive.

Keywords: expanded cinema; spectator; museal space; reception aesthetics. 


\section{Apresentação}

Na criação de obras para o espaço expositivo do museu que se associam aos recursos do cinema, duas temporalidades distintas se unem e se assentam diante da disposição do espectador. Essas obras que caracterizam a transposição do cinema para os espaços expositivos institucionais, como os museus e galerias de arte, em oposição ao cinema de projeção das salas escuras, foram denominadas pelo crítico Jean-Christophe Royoux (apud LINS; FRAGA, 2012) de cinema de exposição.

Considerando que a sensibilidade do indivíduo conforma-se também segundo os aspectos e as criações de sua época, a disponibilidade para a experiência de fruição dos objetos artísticos, no que se refere ao tempo que se dedica ao objeto apreciado, é peculiar a cada espectador. Atualmente, tal disponibilidade é, em grande parte, conformada pelo ritmo acelerado da vida moderna e pela ausência da prática da contemplação, que pode ter formação em uma visualidade baseada nos padrões televisivos e nos filmes de ação.

Para o teórico Thomas Elsaesser (2011), a entrada do cinema no museu permite uma construção particular de uma economia de tempo dos visitantes da exposição. Na visão do autor, ainda que os visitantes do museu destinem apenas alguns minutos frente a uma obra durante a exposição, as instalações que utilizam a imagem em movimento retêm mais a atenção do espectador comum do que as obras tradicionalmente expostas no cubo branco. O cinema de exposição, nessa perspectiva, seria também responsável pelo incremento do tempo de fruição dos indivíduos no espaço dos museus e das galerias de arte.

Neste artigo, visamos empreender reflexões sobre como se estabelecem as práticas espectatoriais de obras de cinema de exposição, a partir de conceitos como cinema expandido (PARENTE, 2006) e de espectador pensativo (BELLOUR, 1987). Trata-se de analisar a relação entre o tempo da obra e o tempo do espectador diante de filmes de longa temporalidade no espaço do museu. Com esse objetivo, dialogamos com autores como Arlindo Machado (1997), Edmond Couchot (2003), Laura Mulvey (2006), Thomas Elsaesser (2011), Jacques Rancière (2012), dentre outros, em suas reflexões sobre o espectador e as possíveis relações de temporalidade tecidas pela fruição das obras.

\section{O Espectador, o Museu e o Cinema}

As galerias e os museus apresentam-se, no que tange à sua relação com o espectador, como espaço de arquivo, mas também de construção de território disciplinar: são um campo privilegiado da arte e de seu sistema. O acervo da instituição artística é fruto da tarefa de conservar determinados aspectos, instâncias e elaborações individuais e sociais, estabelecendo uma transubstanciação de determinadas ocorrências, de elaborações de conhecimento, de discursos hegemônicos e de visões peculiares de mundo em objetos de significação. O acervo reconhece a existência ou o valor de determinadas obras 
e práticas, adequando-as aos discursos que compõem a história e a constituição cultural de determinada sociedade. A esse acervo somam-se as proposições artísticas atuais, que dialogam com o discurso representado pelo acervo e deslocam-se nele.

Cada nova obra que adentra um espaço museal relaciona-se com o que ali antes já estava presente, deslocando intencionalidades e significações, presentificando-as a partir do entendimento de sua representação do passado na construção da atualidade. Ao adentrar galerias ou museus, o espectador, mesmo sem disso se aperceber, entra em contato com as práticas discursivas de uma sociedade. As obras ali expostas são criações de uma realidade histórica e social, posto que a arte constrói-se nos atravessamentos das instâncias sociais (política, econômica, de conhecimento, etc) que contribuem na estruturação de significações.

Porém, isolados por paredes que qualificam as galerias e museus como cubos brancos, esses atravessamentos são, inicialmente, pouco reconhecidos pelo espectador que muitas vezes cruza os espaços com olhos de quem procura por curiosidades. Aqui nos referimos ao espectador não especializado e que carrega consigo "o conflito essencial da lógica perceptiva da modernidade" (CRARY, 2004, p. 76). Esse espectador mantém a tensão entre o olhar funcional, olhando a realidade de modo pragmático, incluindo nessa realidade a necessidade de conhecer a arte, e o olhar instável, prenhe de subjetividade e das derivas possíveis às realidades, sugeridas na fruição das obras.

Em muitos casos, o espectador, ao destinar tempo de apreciação às obras, não segue padrão ou indicação previamente determinados, desconsiderando as significações resultantes da constituição do acervo como espaço de imersão em temporalidades e de multiplicação de discursos. Ele toma para sua atenção as obras que deseja, dedicando a elas um tempo pessoal e subjetivo. O espaço do museu, em si, não empreende uma formulação de ambiente que defina a atenção do indivíduo. Seu percurso pode ser de grandes pausas e imersão pessoal em uma obra ou simplesmente de uma deambulação compromissada apenas com a curiosidade do olhar.

Contrário a essa deambulação diante das obras de arte, o tempo de atenção do espectador no cinema é determinado pela duração da sessão, tempo em que ele permanece estático diante do movimento das imagens. O espaço de referência para a projeção de filmes, nesse contexto, é a sala escura: o silêncio durante as sessões, o projetor, a tela e o escuro da sala fazem parte do dispositivo que produz a sensação de imersão no espectador. Nele, convergem três dimensões diferentes: a arquitetura da sala herdada do teatro italiano, a tecnologia de captação e reprodução cujo padrão foi criado no século XIX e a forma narrativa adotada por filmes no início do século xx, que se mostra, sobretudo, no filme de formato hollywoodiano (PARENTE, 2009).

Jean Louis Baudry (1978), na década de 70, tratou do processo de identificação do espectador na recepção do cinema. Para o estruturalista francês, a ideia de equivalência entre a imagem e o real é uma idealização, uma articulação ideológica. Dessa forma, 
utilizando a psicanálise lacaniana, o autor fala que o dispositivo cinematográfico (projeção, sala escura, imobilidade do espectador) reencena o estágio de espelho, no qual uma criança na fase entre 8 e 18 meses, ao ver-se no espelho, identifica-se como sujeito frente à imagem do seu corpo unificado. "O espectador se identifica menos com o que é representado no espetáculo do que com o que produz o espetáculo; com o que não é visível, mas torna visível (...." (ibidem, p. 25). ${ }^{1}$

A condição do espectador seria de passividade, em um estado próximo ao de sonho e de alucinação. Esse pensamento de Baudry (ibidem), como acusa Parente (2009), ignora as transformações históricas do dispositivo e deixa de lado a organização discursiva do cinema.

Arlindo Machado (1997) expõe que, na sala escura de projeção, o espectador torna-se uma espécie de voyeur ao observar a construção sobre a realidade apresentada no filme:

Ainda hoje, o prazer do filme não pode ser dissociado de uma inevitável pulsão escópica: quando estamos no cinema, submetemos a imagem - a imagem do outro - a um olhar concentrado e bisbilhoteiro. A escopofilia, pulsão de tomar o outro como objeto, submetendo-o a um olhar fixo e curioso, [...] o olhar [...] que se satisfaz em ver o outro objetivado. (MACHADO, 1997, pp. 124-125)

Machado (ibidem) observa ainda que tal comportamento se configura como um dos componentes de maior sedução do cinema. O cubo negro com tela luminosa equivale então a um obscurantismo do espectador que olha anonimamente para a realidade reificada no filme. Este apresenta, portanto, uma possibilidade de estar em uma realidade construída na trama sem se arriscar a fazer parte dela: um estar/não estar que produz certa imersão.

Tais filmes podem apresentar temporalidades manipuladas, nas quais passado, presente e futuro não se distinguem de modo linear, mas rearranjam-se de modo a fornecer ao espectador a visualidade sobre os acontecimentos da realidade criada. Essa manipulação da sequenciação temporal foi tratada por Gilles Deleuze (1990) como imagem-tempo. Essa ideia torna-se bastante adequada para pensar a relação entre a extensão temporal de alguns filmes que fazem parte do cinema de exposição e a consequente alteração do tempo de fruição do espectador do museu. Segundo Viegas (2010),

[...] a imagem-tempo é uma representação direta do tempo através de mecanismos cinematográficos concretos: o flash-back, o faux-raccord, a profundidade de campo, a dessincronização, não dizendo respeito à sucessão temporal horizontal das dimensões passado-presente-futuro, antes pelo contrário, dizendo respeito ao tempo não cronológico, subjetivo, de dimensões coexistentes. Ontologicamente, esta imagem é tempo puro, é a coalescência de passado, presente e futuro.

O espectador é envolvido, sonora e opticamente, num campo sensível e subjetivo, de memórias e ações atuais que constroem a noção de complexidade e profundidade da trama

1 "Le spectateur s'identifie donc moins avec le représenté, le spectacle même, qu'avec ce qui met en jeu ou met en scène le spectacle; avec ce qui n'est pas visible mais fait voir du même mouvement que lui (...)" (BAUDRY, 1978, p. 25). 
e de seus personagens. Esse recurso, porém, nega a similaridade da peça cinematográfica à realidade atualizada do espectador, fugindo de um pretenso realismo e rompendo com a estética da transparência na medida em que mostra ao espectador que se está diante de um filme, e não diante dos acontecimentos diários, por exemplo. Trata-se de uma exibição do dispositivo, e não mais de um ocultamento que proporcione a imersão. Entretanto, outra forma de imersão é efetuada: a da interioridade, uma vez que o espectador constrói em sua interpretação as percepções e afecções daquilo que experimentou tanto na imagem como na trama fílmica.

\section{Do cinema ao museu: fundamentação teórica}

O cinema tradicional foi chamado de forma cinema por Baudry (1978), modelo estético hegemônico, determinado histórica, econômica e socialmente. Para André Parente (2006), porém, a forma cinema está por todos os lados, seja na sala escura ou fora dela; está presente na televisão, na internet, no museu e na galeria de arte, bem como nas pinturas icônicas pós-modernistas dos anos 1970 e 1980, na fotografia e na história em quadrinhos. Mesmo que o termo cinema expandido - proposto por Gene Youngblood (1970, p.35) na década de 1970 para expressar o alargamento do conceito e do ambiente do cinema, que vem acontecendo nas últimas décadas, notabilizando-se pela convergência de linguagens, por seu caráter híbrido — tenha se referido aos ambientes virtuais, vídeo-arte, sites specifics, instalações, dentre outras formas, para Parente (2006), a concepção de cinema expandido está presente sobretudo nas obras que operam na esfera das instalações. Pelo que discorre o autor, o cinema expandido caracteriza-se por duas vertentes: as instalações que reinventam a sala de cinema em outros espaços e as instalações que radicalizam processos de hibridização entre diferentes mídias. Se o cinema experimental procura explorar as possibilidades técnicas do cinema e a videoarte utiliza-se da imagem eletrônica, o cinema expandido é o próprio cinema de forma ampliada (idem, 2009). Tal ampliação do cinema, segundo Bellour (1997), iniciou-se com as instalações audiovisuais expostas nos museus e galerias na década de 1960, que assinalam a passagem do audiovisual para as artes plásticas.

A forma ampliada do cinema, exposto em museus e galerias, promove, pelo pensamento de Elsaesser (2011), uma nova conformação na atenção do espectador. Segundo o autor, a atenção dos visitantes é ampliada com a projeção do cinema no museu, uma vez que eles dedicam a estas obras mais tempo que às pinturas e esculturas. Deste modo, as obras que apresentam longa duração confrontam-se com a temporalidade dos espectadores (e sua mortalidade), constituindo-se como uma forma ativa de resistência do cineasta ao olhar breve e à rápida apropriação pelo visitante informal do museu. Alguns cineastas-artistas ou artistas-cineastas adaptaram-se a essa atenção aleatória por meio da utilização da montagem, da justaposição, do corte rápido e do looping, dentre outras 
formas, como modo de inserir um conceito e outra espécie de narração às suas obras. Esses dispositivos e procedimentos de criação seguem a atual necessidade de formação de novos arranjos perceptivos, engendrados nas proposições técnicas atuais e que conformam novos modos de significação, conforme apresenta Couchot (2003, p. 141):

As tecnologias mudam somente as condições de criação artística, do trabalho de imaginação criadora [...] Mas elas as mudam radicalmente ao mesmo tempo em que elas trocam também as condições de produção e de circulação de sentido.

Uma vez que as tecnologias modificam radicalmente as condições de produção e circulação de sentido, evidencia-se a necessidade de novos procedimentos, imbricando-se no aspecto relacional entre obra e espectador (BOURRIAUD, 2009). Assim, tais proposições artísticas geram outras práticas de fruição e renovam o papel do espectador. As condições contemporâneas de visualidades dos espectadores solicitam a invenção de objetos que motivem a sensibilização concernente à ação atual. A obra de arte, desta forma, deve organizar-se em uma construção formal que expanda e interiorize a interpretação das realidades materiais pelo indivíduo, criando novos arranjos perceptivos que resultem em paradoxos frente a essas realidades a fim de fundar uma "concepção ativa da sensibilidade como instância espontaneamente produtiva" (MARTINS, 2008, n.p.), aquilo que Couchot (2003, p. 141) nomeou como uma mudança na "economia simbólica" e que articula de modo diferente as relações entre obra, autor e espectador.

Sobre a relação do espectador com a arte e as significâncias que esta produz, Jacques Rancière (2012), em O espectador emancipado, expõe que o espectador é responsável por tornar a arte produtiva e assim dar-Ihe sentido. Ou seja, o espectador não pode ser entendido como passivo diante de um objeto, mas como alguém que de alguma forma usufrui desse objeto, ao menos para construir uma referência. A emancipação do espectador, portanto, não se refere, para Rancière (2012), a um processo de recusa de determinado objeto, mas a um procedimento de filtragem que se dá em contato com ele. O espectador, tal como o aluno em relação ao seu mestre, age selecionando, comparando e interpretando.

As adequações de obras do cinema para o museu, conforme Elsaesser (2011, p. 111), têm dado origem a novas formas de envolver o espectador, formuladas em articulações conceituais, ambientais e interativas que fornecem outros atrativos que estão além do cinema clássico e do museu. É o caso dos ambientes sonoros (Jean-Marie Straub/Danièlle Huillet e Janet Cardiff/George Bures Miller) e das composições que tornam palpável a ausência como presença (Christian Boltanski). O cinema então se desterritorializa para aparecer em novos cenários, ampliando sua abrangência para além das salas tradicionais de exibição.

Ainda nesse contexto, recursos oriundos da prática cinematográfica são utilizados para oferecer possíveis formas de subjetivação e interação com os espectadores. A fotografia, por exemplo, insere-se no fluxo da imagem em movimento por vezes com esse objetivo. Sobre isso, Raymond Bellour (1984), em O espectador pensativo, fala que 
o rompimento do ritmo provocado intencionalmente no interior do filme (para enquadrar a imagem fixa fotográfica) desfaz a lógica da imagem em movimento. Essa quebra do fluxo cinematográfico agrega por "subtração": a foto subtrai a ficção do cinema ao mesmo tempo em que acrescenta informações. Esse efeito teria a função de suavizar relativamente "a histeria" da imagem em movimento, mesclando tempos que nunca se confundem. O espectador desses filmes estabelece um ponto de reflexão ao encontrar na imagem em movimento uma imagem fixa. Com a utilização desse recurso, expõe o autor, o espectador deixaria de ser considerado passivo para dar lugar a um espectador que reflete devido ao tempo para apreensão e ponderação sobre a informação transmitida pela paragem da imagem, configurando-se, assim, como um espectador pensativo.

Para Laura Mulvey (2006), quando o espectador tem controle sobre a exibição, com a possibilidade de paragem ou desaceleração da imagem, outra relação de percepção das imagens surge. A autora propõe o conceito de Cinema Lento (Delayed Cinema) para tratar da desaceleração do filme com o intuito de fazer surgir detalhes que antes estavam escondidos, ampliando a percepção da imagem. Para ela, tal conceito, característico do cinema contemporâneo, apresenta-se como perspectiva possível para pensar a musealização do cinema. Se com o cinema narrativo clássico o espectador era passivo ou voyeur, com a paragem da imagem e a possibilidade de manipulação da exposição o espectador passa a ter um papel ativo: "O espectador fetichista controla a imagem para dissolver o voyeurismo e reconfigurar a relação de poder entre o espectador, a câmera e o ecrã, bem como entre macho e fêmea." (MULVEY, 2006, p. 167)

Thomas Elsaesser (2011) discorre sobre algumas contradições que se apresentam no interior da união do cinema com o museu. Uma delas diz respeito à ansiedade nele gerada pela apreciação de filmes de longa duração. O espectador possui a preocupação com o "momento-chave" do filme, uma vez que no museu o tempo disponível se torna reduzido para a observação de cada instalação ou objeto. No entanto, o autor considera que o silêncio aurático do ambiente de galerias e de museus transporta o espectador para o interior de um espaço que se torna um refúgio, "um útero", ou ainda, um espaço de protesto contra um mundo que se movimenta sem controle. A articulação desse silêncio com a concentração sobre a imagem em movimento contrapõe-se à dispersão do espectador gerada na deambulação e na pouca atenção anteriormente dedicada às obras tradicionais.

\section{The Clock (2010), Christian Marcley}

Christian Marclay (1955) é um artista visual e compositor. Em sua instalação, The Clock, ele apresenta uma montagem em loop, com duração de 24 horas, que funciona também como relógio. A ideia foi desenvolvida em 2005 e teve sua estreia em 2010 na galeria White Cube. 
The Clock (2010) consiste em uma montagem de recortes de filmes cinematográficos, em cenas que fazem acompanhar a passagem do tempo, marcada em relógios. Ou seja, as cenas apresentadas contêm uma indicação do tempo cronológico sincronizado com o tempo de exposição, numa edição que se prolonga por 24 horas. Não existe na obra um "momentochave", uma vez que a qualquer momento que o observador chegar estará sincronizado com a hora marcada no filme. A materialização do tempo na tela permite que, independentemente do tempo investido na fruição, o espectador possa estar conectado ao tempo da obra.

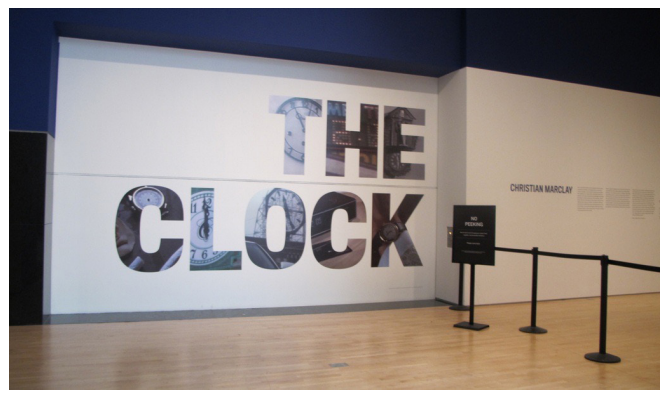

Fig.1. Entrada do sítio de exposição da obra The Clock no SFMoMA, São Francisco, 2013. Fonte: https://exhibitioninquisition.wordpress.com/2013/04/11/christian-marclays-the-clock-part-2/

A obra desafia o espectador e o espaço museal pela sua longa duração. Ela também causa certa sedução, investindo na utilização da plasticidade do cinema, uma vez que é apresentada em uma grande tela de projeção em sala escura, que obedece aos parâmetros solicitados pelo autor. Seu recurso mais notório é o da montagem, que sequencia trechos de diferentes filmes, induzindo a pensar sobre questões de tempos, sincronizações e percepções, bem como sobre as afecções advindas da vivência do passar do tempo. A apresentação de todo tipo de sensações e de comportamentos - apreensão, ansiedade, tranquilidade, tensão, alívio - , derivados de como as diversas situações que envolvem o tempo desenrolam-se na tela, incitam uma espécie de jogo entre os personagens e o espectador ou o conjunto de espectadores da obra.

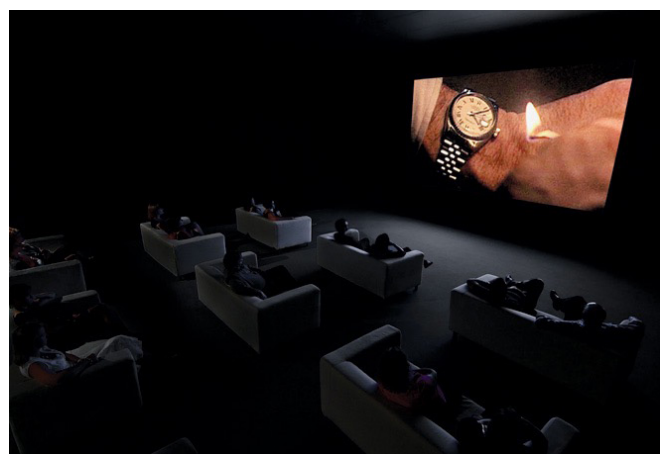

Fig. 2. Ambiente de exibição em The Clock (2010), Christian Marclay. Créditos: (C) Christian Marclay / Courtesy National Gallery, Canadá. 
O espectador acompanha a obra consoante ao tempo atual. A sequência de cenas, recortadas de filmes de várias épocas, proporciona à obra uma profundidade desenhada pelos diferentes modos de ação e reação dos personagens, derivados de comportamentos espacial e temporalmente ancorados em seus territórios existenciais. Ao mesmo tempo, evoca-se um aplainamento de tempos diversos em uma linearidade, nivelando-os todos pela presentificação por meio da sincronização entre os tempos da obra (demonstrados pelos relógios do filme) e o do espectador. A exibição dos relógios realiza-se no plano subjetivo, pelo qual a câmera substitui o olhar do protagonista. Mais ainda, por este plano, o próprio espectador toma o lugar do protagonista. Uma determinada quebra do fluxo cinematográfico é causada pela exposição dos relógios, uma vez que a imagem detém-se, mesmo que seja por pouco tempo, para que se possa verificar a hora marcada no relógio. Esse recurso disponibiliza ao espectador, pela estagnação da imagem, maior tempo para apreensão e ponderação sobre a informação transmitida, configurando o observador, no dizer de Bellour (1984), em um espectador pensativo.

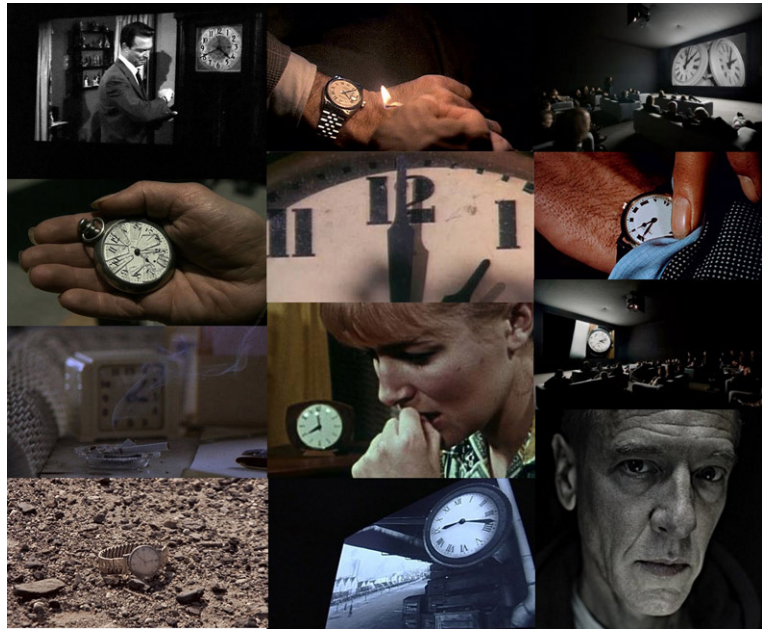

Fig. 3. Christian Marclay. The Clock (detalhes), 2010. Stills de video. Créditos: (C) Christian Marclay / Courtesy Paula Cooper Gallery, New York.

A interação é intrínseca à obra e mesmo que não se possa referir precisamente à análise de Couchot (2003) sobre os objetos artísticos construídos com a utilização do computador e a possibilidade interativa decorrente desse uso, na obra de Marclay a interatividade revela-se na construção temporal da fruição da obra: ao verificar a mesma hora dos relógios retratados na obra em seu relógio pessoal, o espectador é provocado na percepção do tempo real. O sentido e a existência poética da obra realizam-se nessa sincronia entre a figuração do passar do tempo pelos relógios expostos e o momento em que o espectador está a assistir a imagem temporal construída pelo artista. 
"Quando nas três dimensões de tempo às quais se está habituado acrescenta-se aquela do tempo real, certas condições são reunidas para que os alicerces de uma nova cultura se constituam." (COUCHOT, 20003, p. 140). Uma cultura que também envolverá a geração de outros modos de percepção e afecção dos objetos, incluindo os artísticos.

A sincronização com o tempo real bem como a sequenciação ininterrupta de 24 horas da obra levanta ainda outra questão pontuada por Couchot (ibidem) pela qual obra e espectador não ocupam "posições estritamente definidas e estanques", uma vez que, raramente, algum espectador acompanhará toda a temporalidade da obra. A obra apresentará "estados potenciais e estados reais que fazem de cada leitura um acontecimento singular e único" (ibidem, p.141), visto que as sensações e significados de cada indivíduo serão concernentes às imagens visualizadas por ele quando da sua presença no espaço da obra, considerando ainda o tempo dedicado a essa visualização. A obra, portanto, está disponível aos significados peculiares dados pelo espectador, conforme expõe Couchot (ibidem, p. 137):

É esta conformação dramática [do espectador a uma sujeição perceptiva] que torna a existência e a significação da obra dependentes da intervenção do espectador. A obra não é mais fechada sobre si mesma, fixa no seu acabamento, ela "se abre".

Esse pensamento de abertura da obra pode levar-nos à reflexão sobre a autonomia do espectador em sua fruição. Para Rancière (2012, p.52), mesmo que haja uma relação de causa e efeito entre o trabalho do artista e a reação do espectador, a fruição realizada não decorre de uma predeterminação dada pelo artista, compondo-se na sensibilidade peculiar do indivíduo.

\section{Theresienstadt (2007), Daniel Blaufuks}

Daniel Blaufuks (1963) nasceu em Lisboa. Seu trabalho parte de uma pesquisa sobre a relação entre fotografia e literatura, tendo forte influência da história dos judeus durante o nazismo, principalmente por pertencer a uma família de refugiados judeus alemães. Em um dos seus filmes, Theresienstadt (2007), Blaufuks reúne fragmentos de um filme realizado por nazistas em Terezín, pensado para ter a duração de 90 minutos. Tal duração foi considerada suficiente para convencer que o campo de concentração era um lugar onde os judeus eram bem tratados e viviam normalmente com seus afazeres. Blaufuks encontrou 20 minutos desse filme e, recorrendo ao efeito de câmara lenta, desacelerou os fragmentos até o filme retomar o tempo original de 90 minutos. Acompanhado de uma tintagem vermelha das imagens, em contraste ao preto e branco do filme original, como resposta à horrenda realidade encoberta pelos nazistas, Blaufuks apresentou Theresienstadt em museus e galerias. 


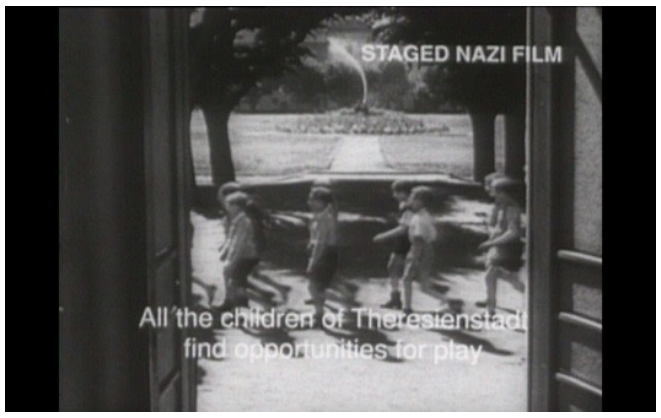

Fig. 4. Fragmento do filme nazista realizado em Theresienstadt. Fonte: Reprodução

A proposição de abertura da obra por meio de uma transformação da imagem e da consequente apreensão visual do espectador pode também ser observada na criação da obra Theresienstadt (2007). Segundo David Santos (2014), Blaufuks trabalha com uma "temporalidade total" com o uso de imagens documentais. Ao unir todos os fragmentos encontrados de Terezín, o artista isenta-se da "angústia da escolha" (idem), pois escolher entre os rostos que ali aparecem seria como um trabalho de polícia. $\mathrm{O}$ artista explora todos os fragmentos que restaram, esticando-os numa velocidade quatro vezes menor até ficarem quase estáticos para restabelecer o tempo total do filme original. O desaceleramento das imagens, característico do cinema contemplativo contemporâneo (Delayed Cinema), proposto por Mulvey (2006), faz com que detalhes antes escondidos surjam, ampliando a percepção diante da imagem. Essa desaceleração permite um tipo de relação fotográfica com a imagem, fazendo com que as expressões e gestualidades tornem-se visíveis em seus detalhes na superfície do ecrã.

A fotografia ecoa ainda uma ideia de fidelidade, de verossimilhança, apesar das desconfianças de sua suposta realidade. Mesmo de modo inconsciente, o espectador conecta a fotografia ao "isto foi" barthesiano, ou seja, há uma crença na verdade que surge na superfície da imagem pela sua ligação com algo que existe ou existiu. No entanto, por saber da insuficiência da imagem para veicular a verdade, Blaufuks tenta encontrar uma veracidade nos excertos da obra nazista ao recuperar a suposta duração original do filme, "numa tentativa de repor alguma espécie de dignidade em torno da necessidade de esclarecimento das imagens, resgatando-as do esquecimento." (SANTOS, 2014, p. 26) Trata-se, assim, de uma arte política, tal como propôs Rancière (2012), pois mostra a mancha deixada na história pela dominação nazista. 

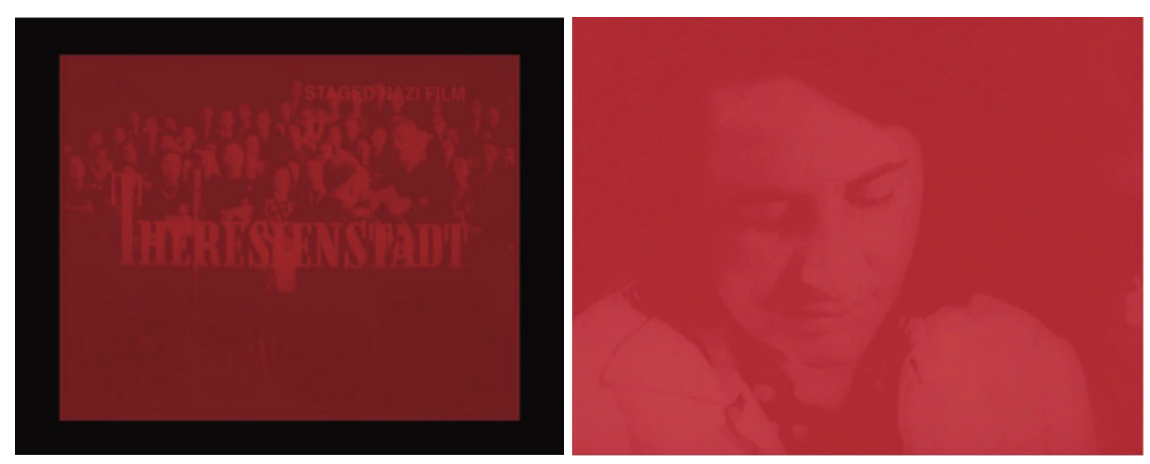

Figs 5 e 6. Daniel Blaufuks. Terezín, 2007. Still de vídeo (90', loop) Fonte: http://www.danielblaufuks.com

Ao permitir a "ascensão de situações puramente ópticas (e sonoras) fundamentalmente distintas das situações sensório-motoras da imagem-ação do antigo realismo" (DELEUZE, 1990, pp.11-12), o filme possibilita experienciar a recepção das imagens numa corrente contrária à do cinema narrativo americano. O ritmo lento do filme de Blaufuks trabalha a experiência visual do cinema ao obedecer a um paradigma puramente temporal. O autor, ao unir fragmentos dispersos do filme nazista, dispondo-os em uma sequência que não é a da narrativa original, envolve o espectador em uma situação puramente óptica, acentuada pela duração lenta do filme. Na obra de Blaufuks o tempo das imagens não obedece a uma ordem cronológica, mesmo que se imponha uma sequência de planos, "ao tempo é deixada a força principal da ligação entre as imagens, assumindo uma sensorialidade quase táctil." (SANTOS, 2014, p. 26)

Quando o enquadramento da câmara recorta determinado momento no espaçotempo, sabemos que aquele tempo não retorna. No entanto, o tempo congelado pelo registro tem como maior sedução a possibilidade de, a cada investimento do olhar, fazer surgir um pormenor que nos proporciona a reconstituição do tempo, que reaviva a nossa memória incompleta e lacunar. As imagens dos judeus no filme nazista são apropriadas objetivando-se trabalhar a densidade do tempo para a reconstrução de uma memória: "Uma imagem não é obrigatoriamente produzida para o presente, mas eventualmente para o futuro, quando poderá ser recontextualizada incessantemente." (BLAUFUKS, 2014, p. 92) 


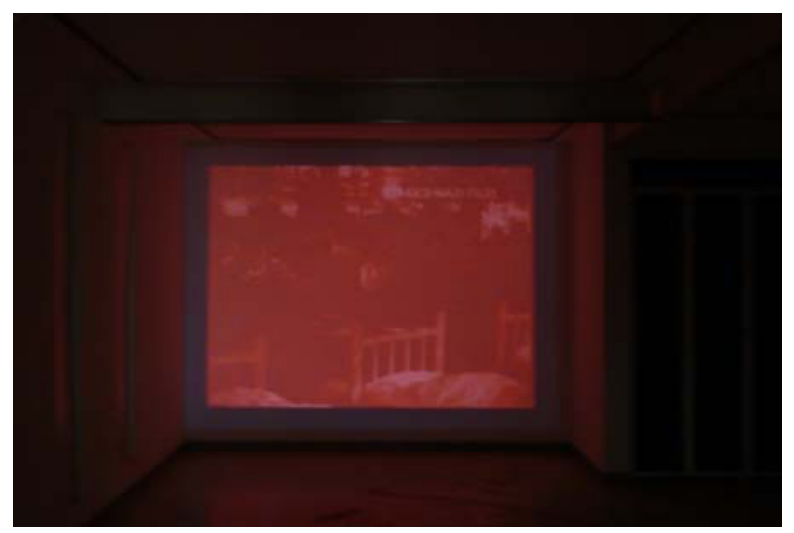

Fig. 7. Daniel Blaufuks. Terezín, 2007. Sala de projeção de vídeo (90', loop) Fonte: http://www.danielblaufuks.com

O espectador, apesar de não ter o controle das imagens que se desdobram nessa obra, ao assistir à quase paralisação das imagens, encontra uma pausa para reflexão e apreensão da informação transmitida, tornando-se um espectador pensativo. Nesse balanço, o espectador trabalha com as imagens que são vistas e com a memória que completa as lacunas do que se vê, mediante o tempo investido para observação da obra. Theresienstadt, apesar de sua duração extensa, é constituído por fragmentos aleatórios, que, como toda imagem-tempo, não possui um tempo cronológico, tendo sido feita para dar a ver e sentir. Assim, o artista encontra na obra uma forma temporal que, independente do tempo investido pelo espectador, repõe sua carga sensível com a visualização de cada fragmento. Cada fragmento é já um "momento-chave", uma repetição, e serve também para desacelerar a ansiedade imposta por filmes essencialmente narrativos. O tempo do espectador não se encontra com o tempo da obra, como em The Clock. O tempo não está materializado na tela, mas surge aqui como matéria trabalhada pelo autor na obra. Assim, a atenção aleatória do espectador no ambiente do museu, independentemente do tempo investido para fruição, pode tornar-se satisfatória para compreensão da obra, visto que a mesma história repete-se em cada fragmento vermelho e quase estático do filme. Ao mostrar os rostos lentos e os movimentos frágeis daqueles judeus que aparecem no filme, Blaufuks permite-nos resgatar Terezín do esquecimento e reanima aquelas pessoas em nossa memória.

\section{Considerações finais}

No espaço museal existe uma configuração específica espaço/temporal diversa do cinema, que atribui à obra um caráter de entidade, de acontecimento único. A fruição da obra realiza-se num espaço não imersivo, uma vez que o espectador define o tempo dedicado à obra; principia essa experiência, porém, no assentimento sobre o valor das obras que ali estão e a formação de território que esse espaço materializa. 
$\mathrm{Na}$ associação entre cinema e museu, as composições apelam à manipulação das imagens em movimento, conformando diferentes modos de temporalidade. Tais construções cinéticas promovem a revisão da ação do espectador no museu uma vez que a imagem em movimento requer um tempo maior de observação em relação às imagens estáticas por sua própria característica de não dizer tudo em um só frame, ainda que cada cena seja uma repetição desse mesmo frame. Porém, conquanto que a imagem-fluxo no museu requisite do observador maior tempo de observação, esse tempo, como anteriormente dito, não é controlado como no espaço do cinema: o resultado disso parece ser uma convocação mais incisiva do espectador, proporcionando-Ihe autonomia.

Ao tratarmos de obras fílmicas de longa duração expostas no museu, colocamos em evidência a composição artística que provoca a mobilização do tempo do espectador. Os recursos tecnológicos utilizados pelo artista, ao mudarem as condições de sua criação, modificam as formas de construção e circulação de sentido (COUCHOT, 2003, p. 141). O uso de novos recursos e procedimentos técnicos considera a necessidade de transformação da visualidade atual dos indivíduos, cuja formação é submetida ao aceleramento de tempos e de procedimentos e aos bombardeamentos dos recursos da imagem em movimento, principalmente de cunho comercial.

As técnicas utilizadas em suas criações visam a proporcionar a construção de um espectador emancipado, pensativo, cuja ação em relação à obra é de produção. O tempo, algo que na contemporaneidade nos é escasso, é o agente motriz dessa construção de produtividade, ressaltando o caráter político que este adquire. Assim, somam-se aos discursos construídos pelos artistas em The Clock e Theresienstadt os questionamentos sobre a instância do tempo e o seu valor em nossa realidade subjetiva e material, uma vez que, segundo Parente (2009, p. 30), "o tempo é o operador que põe em crise a verdade e o mundo, a significação e a comunicação."

A associação entre cinema e museu resulta, a nosso ver, numa aproximação produtiva dos sujeitos aos objetos artísticos, criando paradoxos sobre as realidades atuais de aceleração de ritmos e de obliteração das percepções pelo excesso de imagens televisivas. As obras de longa duração oferecem ao espectador a oportunidade de gerir seu tempo de fruição, assim como, pela longevidade de sua exposição, ampliam seu período de percepção e apreensão. A fruição de tais obras, considerando os recursos utilizados em suas composições, aponta para uma provocação dos indivíduos no que tange não somente aos campos de significância constituídos pelas proposições artísticas, mas também no que diz respeito à natureza das relações que envolvem obra, espectador, autor e espaço da arte na contemporaneidade.

Na perspectiva da gestão do tempo, os artistas-cineastas oferecem-nos oportunidades de questionamentos não somente dentro dos espaços do museu, na fruição de suas obras, mas também nos convocam em nossa sensibilidade a fim de ampliarmos a discussão sobre como, enquanto indivíduos da realidade atual, produzimos nossa ação e apreensão do mundo ao longo de nossa própria temporalidade. 
Cristiane Herres Terraza é docente em Artes Visuais no Instituto Federal de Brasília, pesquisadora (DGP/CNPq/ Brasil) e doutora em Arte pelo PPG-IdA/UnB - Brasil.

crisherres@gmail.com

Lorena Travassos é Mestre é doutoranda em Ciências da Comunicação na Universidade Nova de Lisboa (FCSH-UNL) e bolsista da CAPES.

lorenakrs@gmail.com

\section{Referências}

BELLOUR, R. Le Spectateur pensatif. Photogénies 5. Paris: Centre Nacional de la Photographie, 1984.

BAUDRY, J.L. L'effet Cinéma. Paris: Albatros, 1978.

BLAUFUKS, D. O peso da memória. Toda a Memória do Mundo, parte um. Lisboa: Imprensa Nacional - Casa da Moeda, 2014, pp. 54-60.

BOURRIAUD, N. Estética relacional. São Paulo: Editora Martins, 2009.

COUCHOT, E. A tecnologia na arte: da fotografia à realidade virtual. Porto Alegre: Editora UFRGS, 2003.

CRARY, J. A visão que se desprende: Manet e o observador atento no fim do século XIX. In: CHARNEY, L. \& SCHWARTZ, V. (orgs.), O cinema e a invenção da vida moderna. São Paulo: Cosac Naify, pp. 67-93, 2004.

DELEUZE, G. A imagem-tempo. Rio de Janeiro: Brasiliense, 1990.

ELSAESSER, T. Stop/Motion. In: ROSSACK, E. (ed.), Between Stillness and Movement: Film Photography Algorithms. Amsterdã: Amsterdam University Press, pp. 109-122, 2011.

LINS, C.; FRAGA, I. Revista CH. 20 Out. 2012. Disponível em: http://cienciahoje.uol.com.br/ revista-ch/2012/296/o-cinema-vai-ao-museu/?searchterm=None. Acesso em: 23 Mar. 2015.

MACHADO, A. Pré-cinemas \& pós-cinemas. Campinas: Papirus, 1997.

MARTINS, L. R. Economia política da arte moderna/providências para uma história crítica. São Paulo: ARS, vol. 6. $\mathrm{n}^{\circ}$ 12, jul/dez de 2008. Disponível em: http://www.scielo.br/scielo.php?pid=S16 7853202008000200007 \&script=sci_arttext. Acesso em 22 de Mar. 2010.

MULVEY, L. Death 24 x a second: stillness and the moving image. Londres: Reaktion Books, 2006.

PARENTE, A. Forma cinema: variações e rupturas. In: MACIEL, K. (org). Transcinemas. Rio de Janeiro: Contracapa, 2009.

RANCIÈRE, J. O espectador emancipado. São Paulo: Martins Fontes, 2012.

SANTOS, D. Em busca do tempo disperso ou Toda a memória do mundo em Daniel Blaufuks. In: BLAUFUKS, D. (ed.). Toda a Memória do Mundo, parte um. Lisboa: Imprensa Nacional - Casa da Moeda, pp. 13-38, 2014.

VIEGAS, S. Gilles Deleuze, website do Instituto de Filosofia da Linguagem (IFL, FCSH-UNL). Disponível em http://filmphilosophy.squarespace.com/1-gilles-deleuze, 2010. Acesso em 12 Jun. 2015.

YOUNGBLOOD, G. Expanded Cinema. New York: P. Dutton \& Co., Inc., 1970. 